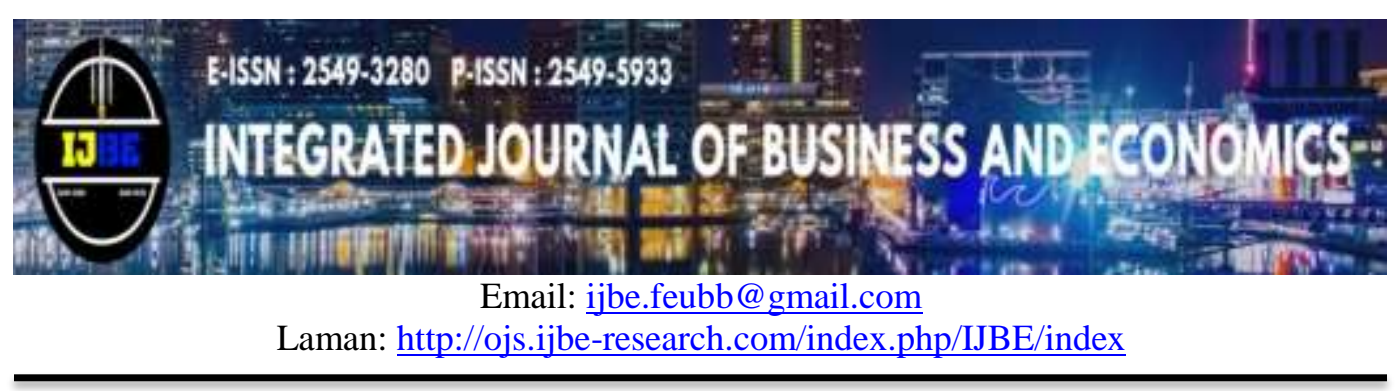

\title{
Customers' Behavior Intension Regarding Online Shopping Of General Product And Insecticide In Thailand
}

\author{
Dinesh Elango $^{\text {a }}$, Kritchanut Prayoonpong ${ }^{b}$ \\ ${ }^{\mathrm{a}, \mathrm{b}}$ Graduate School of Business, Assumption University of Thailand \\ vipdinesh@gmail.com
}

\begin{abstract}
The global market for insecticide products is expected to collect around 16.7 billion US in 2020, registering a CAGR of 5.0\% over the 2014 to 2020 forecast period. The company operates in this market focus on product launches as part of its growth strategy. As global e-commerce retail sales continue to grow, ecommerce has gained a large share of physical retail over the past decade stemming from the impact of greater internet access and technological development that makes online shopping more comfortable and convenient. This study analyzes data on customers' behavioral intentions in parallel, comparing the impact of data from general products and insecticide products. The analysis used is multiple linear regression used to investigate the effects and differences between the dependent and independent variables. Four hundred respondents who used online applications and had online shopping experience implied to examine factors that had the intention to decide on product purchases through online channels in this study.
\end{abstract}

\section{Article Info}

- Received : May 19, 2020

- Revised : June 13, 2020

- Published : June 23, 2020

- No. Pages : 184 - 197

- DOI : 10.33019/ijbe.v4i2.288

- JEL : D22

- Keywords : Insecticide Online, Insecticide Purchase Intention, Behavior Intension of Insecticide, General Product Attitude, General Product Behavior.

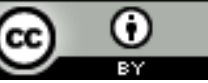




\section{Introduction}

According to the online shopper, are increasing around the globe. Consumers unite and combine their buying power to bargain for a significant volume discount from a seller. On the other hand, it also helps support the new seller to enter the market quickly. This research provides an overview study to examine customers' behavior intension regarding online shopping of general product and insecticide products in Thailand. Moreover, the hypothesis of the study will have constructed corresponding from the questionnaire. Then, the result of the study will present and a brief overview of the survey to the conclusion.

Online shopping has become the most popular Internet activity, immediately following direct massage to customer as advertising during customer use internet. Research will focus on the Thailand market to analysis data of general product and insecticide product which currently, 12.1 million Thais shop online and spend an average of US\$ 243 per year on e-commerce. The annual online expenditure per person is expected to grow to US\$ 382 by 2021, according to research reports (Vasundhara Rastogi 2018). During the same time product category is not popular to find it in Ecommerce market or online market. This item is poisons designed to control specific organisms. The anonymity and remoteness of the parties involved in internet might concern of customers behavior than general product to use online channel to promote and sell in online channel ".

However, the global market of insecticide products is expected to garner around 16.7 Billion US by 2020, registering a CAGR of 5.0\% during the forecast period 2014 to 2020. The Asia-Pacific regional market held over $44 \%$ of the total global insecticides' market in terms of value in the year 2013 (Allied market research,2018). The growth of the business goes through in the same direction which the research focus on behavior intension of the customer to general product and insecticide.

The purpose of this study to examine customers' behavior intension regarding online shopping of general product and insecticide products in Thailand. The study also surveys both attitude and behavior to now customer purchase intention. This study also predicts the consumer's behavior regard to insecticide in online shopping of people in Thailand by comparing data between general product and pesticide.

\section{Literature Review}

The model claim that people tend to perform behaviors that they propose a conceptual framework to identify the relationship between general product and insecticide product. Both independent values are present in the general product and insecticide product as two main factors between Customer attitude and customer behavior. Besides, it will include in-depth information on each variable, along with the support of other researchers. 


\section{Customer Attitude}

Attitude can have defined as a person's overall evaluation of the favorableness of the behavior. It is a valid response at a low level of intensity and arousal. The attributes for measuring these beliefs and assessments of consequences were generated from a review of the literature.

- Product/convenient the concept of convenience in market theory to clarify the outcome. Product/Convenient are products designed to minimize the requirement of the customer to buy the product (Berry et al. and Sieder et al., 2002). The research offered five components of product convenience: variety, information, quality, price, and time when considering the customer's perception of satisfaction in the online and traditional shopping environments (Beauchamp and Ponder, 2010).

- Customer service - defined as a global judgment about the superiority of service. The quality of the electronic service is delivered to consumers, not only via website presence or low price but also on any other factor. (Yang, 2001; Zeit Hemal et al., 2002).

\section{Customer Behavioral}

Perceived behavior control refers to people's perception of the ease or difficulty of performing the behavior of interest. In other words, it is an individual's confidence in his/her ability to perform the action based on the presence or absence of essential resources and opportunities.

Purchase and delivery - the process of buying, selling, transferring, serving, or exchanging products, services, or information via computer networks, including the Internet.

- E-commerce represents a new low-cost channel for both businesses and consumers to communicate and transform information, and many retail stores introduce an online front to reach new consumers (T. Al-Maghrabi And C. Dennis, 2010)

- Reliability - has been measured using reliability, dependability, credibility, and consistency (Butler \& Cantrell, 1984). If a consumer perceives the product as reliable, one believes that the product is sincere about the claims it made for the advertised product or service and that the requests are usually fulfilled.

\section{Purchase intention}

Customer's buying decision is very complex. Normally purchasing intention will related with customer's behavior and attitude. The important key point of the customer is the purchase behavior during considering and evaluating any kind of product (Keller, 2011). Purchase intention is the efficient tool use for predicting of purchase decision of the customer. Their intention decides to purchase the product certain store; however, purchase intention might be altered by the price effect, quality perception and value perception (Zeithaml, 1988). In addition, consumers will be interrupted by internal impulse and external environment during purchasing process. Their behavior will be driven by the physiological motivation that stimulates their respond which bring them to the retail store to fulfill their need (Kim and Jin, 2001). 


\section{Theoretical framework}

The framework is a good measure of behavior that can be obtained from the intention to act (BI) as predicted by the Fishbein behavioral intention model (Fishbein \& Ajzen, 1975). The Theory of Planned Behavior (TPB) is an extension of the Theory of Reasoned Action (TRA) (Ajzen \& Fishbein, 1980; Fishbein \& Ajzen, 1975).

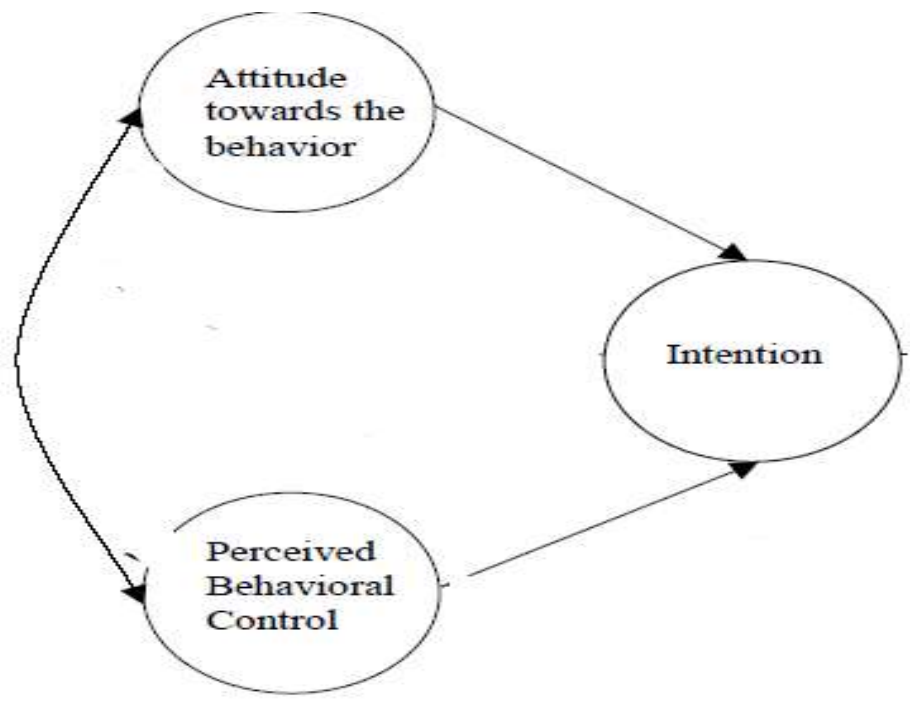

\section{Figure 1: The theory framework model: Customer purchase intension Conceptual framework.}

The concept adapted from the behavioral intention model (Fishbein \& Ajzen,1975), which framework study parallel with insecticide product. For all two constructs indicated in the conceptual model, each independent variable (product/ available and customer service subset of attitudes - product and delivery, reliability, promotion, product attribute and access subset of Behavior) influences the dependent variable (purchase intention) which indicates whether shoppers are more likely to buy products online or not. In the same way, the framework will relate to insecticide products by adding customer criteria to choose insecticide products. There is no behavioral construct in the context since this research intends to find the intention to shop online, not the actual shopping behavior of insecticides framework is a good measure of Behavior that can be obtained from the plan to act (BI) as predicted by the Fishbein behavioral intention model (Fishbein \& Ajzen, 1975). The Theory of Planned Behavior (TPB) is an extension of the Theory of Reasoned Action (TRA) (Ajzen \& Fishbein, 1980; Fishbein \& Ajzen, 1975). 


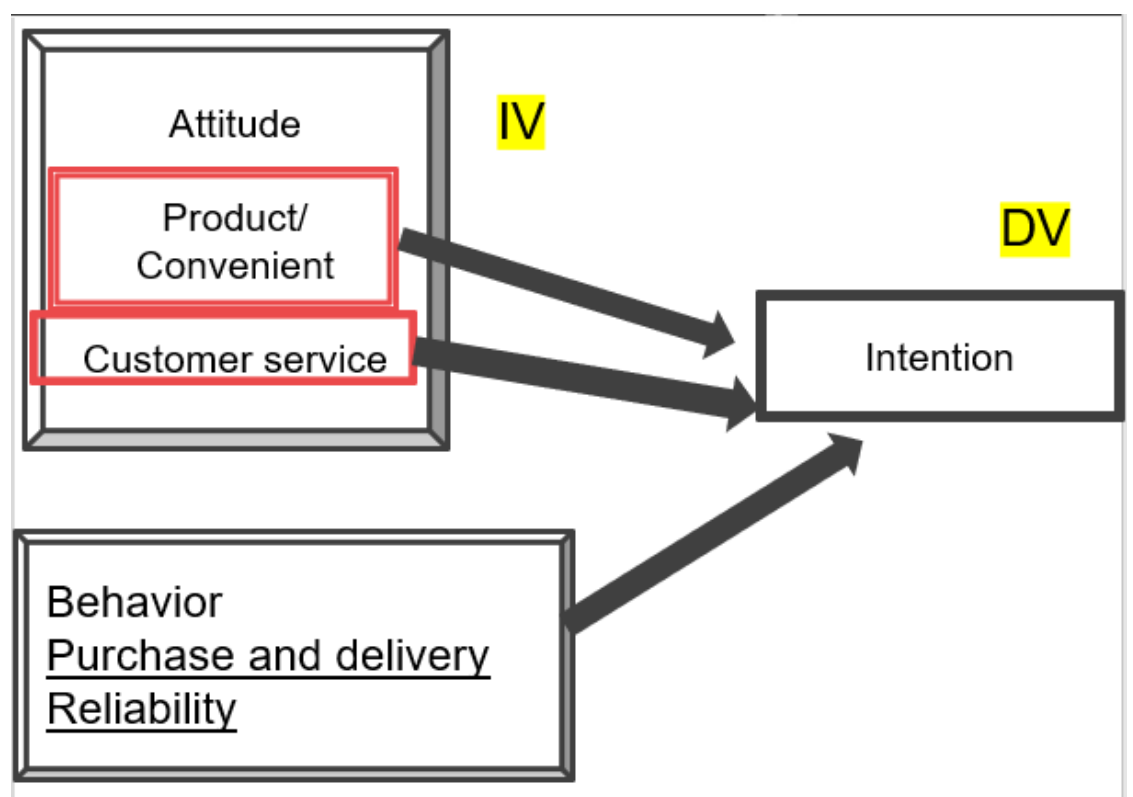

Figure 2: The conceptual model: Customer purchase intension

\section{Hypothesis}

H1: There will be a significant predictor of purchase intention toward universal products via online channels by product/convenience.

H2: There will be a significant predictor of purchase intention toward universal products via online channels by customer service.

H3: There will be a significant predictor of purchase intention toward general product via online channel by purchase and delivery, reliability, promotion, product attribute, and access.

H4: There will be a significant predictor of purchase intention toward insecticide products via online channels by product/convenience.

H5: There will be a significant predictor of purchase intention toward insecticide products via online channels by customer product.

H6: There will be a significant predictor of purchase intention toward insecticide products via online channels by purchase and delivery, reliability, promotion, product attribute, and access. 


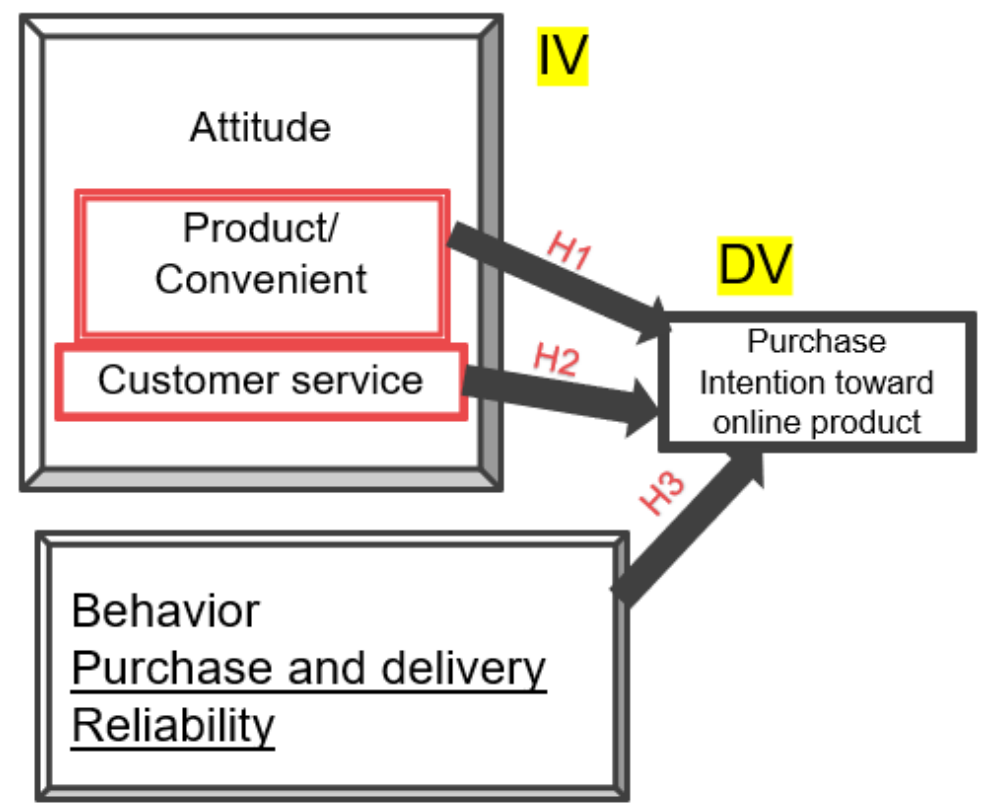

Figure 3: Conceptual research: The attitude and behavior factor effect on purchase intention toward general product.

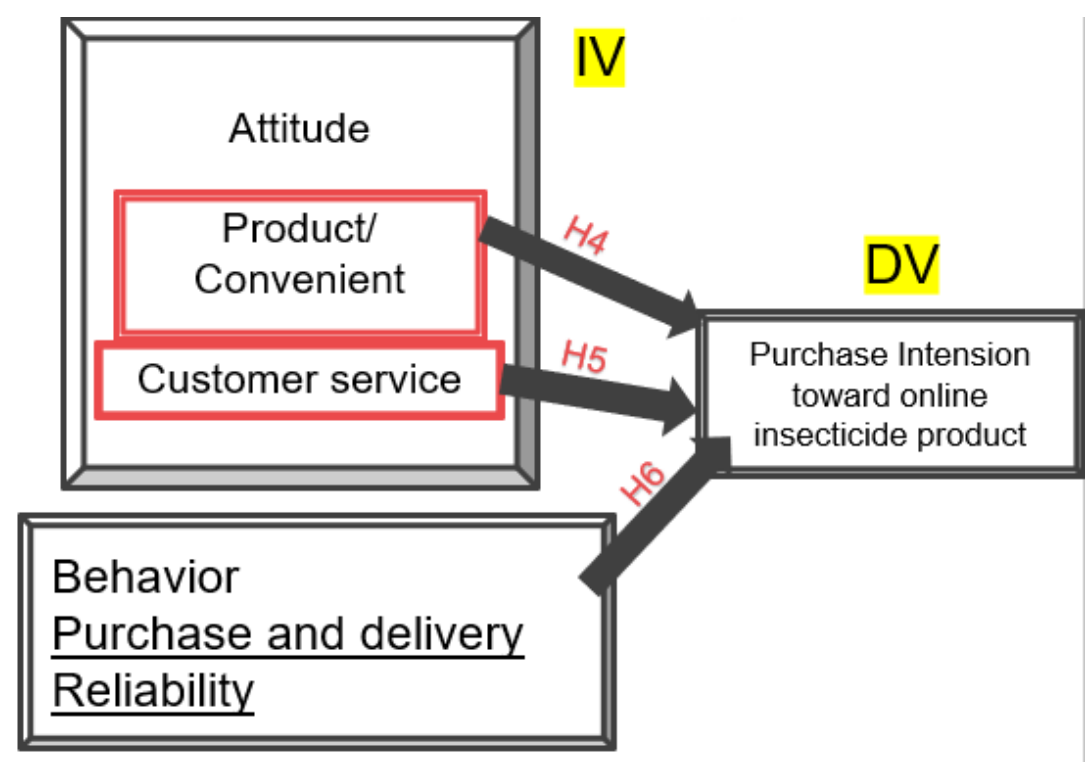

Figure 4: Conceptual research: The attitude and behavior factor effect on purchase intention toward insecticide product.

\section{Research Methods}

This research was adopted in the present research study. It began with in-deep research design and data gathering method used. This research used a quantitative analysis approach with a non-probability way through a survey method in the form of an online questionnaire and purchased Facebook advertising to expand my sampling. There are five parts in the census: screening questions, Likert scale for a general product, Likert level for criteria of insecticide, Likert size for 
pesticide, and demographic data. Five-Point Likert scale is used with range mentioned, five as 'Very important' and one as 'Not important' to measure the hypotheses. Also, use other case studies, news, research paper, reference books, and journals related to the subject as secondary data. Data analysis explains the validating and reliability of the measurement model and assessment of the structural model. Single Linear Regression (SLR) apply for study relationships between variables variable according to the defined conceptual framework. Multiple Linear Regression (MLR) uses several explanatory variables to predict the outcome of response varies according to the defined conceptual framework. And this research also used to determine whether there are any statistically significant differences between the means of the independent variable.

\section{Measurement of variables}

The target respondents are people who use an online network to search for any product.

\section{Population and samples}

Online questionnaires are reached to 400 respondents living in Thailand and have an online shopping application. The respondents are selected by convenience sampling technique, judgment sampling technique, snowball sampling technique, and quota sampling technique. The convenience and snowball sampling technique were applied for the data collection by sending the questionnaires online randomly from the list in the researcher's contact on each platform such as Facebook, Email, etc. and asks respondents to forward the inquiries to whom they know. Moreover, the researcher asked 52\% of respondents who live in Thailand.

\section{Results}

\section{Reliability Test}

To test the questionnaire's reliability, a pilot test was determined by distributing 30 questionnaires to 30 different respondents and different product categories between general product and insecticide products regardless of whether they were out of the target customer. Cronbach's Alpha Coefficient is also practiced determining if the questionnaire is reliable, and all questions for each variable are valid as the Cronbach value is more significant than 0.6 (Cronbach, 1951). The reliability level that passes the qualifications can be implied that the questionnaire developed in this study is given the standard required for reliability test and possible to move the research forward. 
Table 1. Reliability Test

\begin{tabular}{|c|c|c|c|c|}
\hline \multirow{2}{*}{ Variable } & \multicolumn{2}{|c|}{ General product } & \multicolumn{2}{|c|}{ Insecticide } \\
\hline & Cronbach's Alpha & No. of Items & Cronbach's Alpha & No. of Items \\
\hline \multicolumn{5}{|l|}{ Attitude } \\
\hline - Product/Conveniet & 0.636 & 6 & 0.804 & 6 \\
\hline - Customer service & 0.833 & 5 & 0.857 & 5 \\
\hline \multicolumn{5}{|l|}{ Behavior } \\
\hline - Purchase and delivery & 0.696 & 3 & 0.863 & 3 \\
\hline - Reliability & 0.787 & 4 & 0.921 & 4 \\
\hline - Promotion & No value & 1 & No value & 1 \\
\hline - Product attribute & No value & 1 & No value & 1 \\
\hline - Access & No value & 1 & No value & 1 \\
\hline Purchase intention & 0.761 & 4 & 0.594 & 4 \\
\hline
\end{tabular}

Source: data processed (2019)

The result in table 1 illustrated that the Cronbach's Alpha of each variable is more significant than 0.6, which means that the questionnaire has achieved the standard of the reliability requirement and is acceptable to use a questionnaire parallel of general product and insecticide.

\section{Result and Discussion}

Based on the data run parallel run same code but data separate between general product and insecticide.

Table 2. Match Data With Variable Code

\begin{tabular}{|l|c|c|}
\hline \multirow{2}{*}{\multicolumn{1}{|c|}{ Data }} & \multicolumn{2}{c|}{ Variable code } \\
\cline { 2 - 3 } & General product & Insecticide \\
\hline - Product/Conveniet & Aproduct & Inproduct \\
\hline - Customer service & Aservice & Inservice \\
\hline Behavior & & InBpur \\
\hline - Purchase and delivery & Bpur & InBrelai \\
\hline - Reliability & Brelai & InBpromo \\
\hline - Promotion & Bpromo & InBattribute \\
\hline - Product attribute & Battribute & InBaccess \\
\hline - Access & Baccess & InInten \\
\hline Purchase intention & Inten & \\
\hline
\end{tabular}

Source: data processed (2019)

\section{Demographic Profile Summary}

As summarized, the demographic profile summary data of all 400 respondents in the questionnaire are shown in Table 2 below. Overall respondent has the experience to see the product in online shopping because the survey was released only online source such as Facebook sharing, Facebook advertising, Line, and email. The proportion gender of respondents who complete the questionnaire was female at $79.8 \%$ out of the total sampling technique. The central majority of respondents were 25-34 years old was $41.3 \%$ of respondents, and graduate with a bachelor's degree with $46.80 \%$, followed by $29.5 \%$ of master's degree as the status of respondent were mostly single $66.30 \%$ followed by married $32 \%$. Also, the major of respondents were private company office $31 \%$ followed by government or military worker $21.3 \%$ and service worker $15.5 \%$, respectively. In 
the family of respondents have no children member was $72.5 \%$ of the respondent. The most income of respondents collect at each year in the range of more than 45,000 THB per month was $28 \%$, which salary range 35,001 to 45,000 are followed by $20 \%$.

\section{Table 3. Demographic Information}

\begin{tabular}{|c|c|c|c|}
\hline \multicolumn{2}{|r|}{ Demographic information } & Frequency & percentage \\
\hline \multirow{2}{*}{ Gender } & Male & 81 & $20.30 \%$ \\
\hline & Female & 319 & $79.80 \%$ \\
\hline \multirow{8}{*}{ Age } & $18-24$ & 40 & $10.00 \%$ \\
\hline & $25-29$ & 109 & $27.30 \%$ \\
\hline & $30-34$ & 56 & $14.00 \%$ \\
\hline & $35-39$ & 41 & $10.30 \%$ \\
\hline & $40-44$ & 44 & $11.00 \%$ \\
\hline & $45-49$ & 41 & $10.30 \%$ \\
\hline & $50-59$ & 66 & $16.50 \%$ \\
\hline & 60 above & 3 & $0.80 \%$ \\
\hline \multirow{5}{*}{ Income } & 10,001 THB - 15,000 THB & 59 & $14.80 \%$ \\
\hline & 15,001 THB - 25,000 THB & 74 & $18.50 \%$ \\
\hline & 25,001 THB - 35,000 THB & 75 & $18.80 \%$ \\
\hline & 35,001 THB - 45,000 THB & 80 & $20.00 \%$ \\
\hline & 45,001 above & 112 & $28.00 \%$ \\
\hline \multirow{3}{*}{ Status } & Single/never married & 268 & $66.30 \%$ \\
\hline & Married/living with a partner & 128 & $32.00 \%$ \\
\hline & Separated/widowed/divorced & 7 & $1.80 \%$ \\
\hline \multirow{4}{*}{ Education } & Associate or two years college degree & 84 & $21.00 \%$ \\
\hline & Bachelor's degree & 187 & $46.80 \%$ \\
\hline & Master's degree & 118 & $29.50 \%$ \\
\hline & Ph.D 's degree & 11 & $2.80 \%$ \\
\hline \multirow{4}{*}{$\begin{array}{l}\text { Childen } \\
\text { member }\end{array}$} & None & 290 & $72.50 \%$ \\
\hline & Under 6 years old & 34 & $8.50 \%$ \\
\hline & 6 to 11 years old & 26 & $6.50 \%$ \\
\hline & 12 to 17 years old & 50 & $12.50 \%$ \\
\hline \multirow{11}{*}{ Occupation } & Professional or technical & 30 & $7.50 \%$ \\
\hline & Farmer/agriculture & & \\
\hline & Sales worker & 2 & $0.50 \%$ \\
\hline & Manager or administrator & 51 & $12.60 \%$ \\
\hline & Clerical worker & & \\
\hline & Education & 32 & $8.00 \%$ \\
\hline & Machine operator or laborer & 2 & $0.50 \%$ \\
\hline & Service worker & 82 & $15.50 \%$ \\
\hline & Government or military worker & 85 & $21.30 \%$ \\
\hline & Private company officer & 124 & $31.00 \%$ \\
\hline & Student & 12 & $3.00 \%$ \\
\hline
\end{tabular}

Source: data processed (2019)

\section{Testing of Hypotheses}

Regarding the hypotheses, analyze data by using Single linear regression (SLR), Multiple linear regression (MLR), and interpret data under 6 Hypotheses.

Table 4. Single Linear Regression of Attitude Independent Value with Purchase Intention Toward General Product And Insecticide.

\begin{tabular}{|l|r|r|r|r|r|r|}
\hline Independent & \multicolumn{2}{|c|}{ Mean } & \multicolumn{2}{c|}{ Std. Deviation } & \multicolumn{2}{c|}{$\beta$} \\
\hline Attitude & \multicolumn{1}{|c|}{ General } & Insecticide & \multicolumn{1}{c|}{ General } & Insecticide & General & Insecticide \\
\hline Product/Convenient & 4.2233 & 4.2487 & 0.6042 & 0.73311 & 0.627 & 0.686 \\
\hline Customer service & 4.056 & 4.1955 & 0.781166 & 0.82144 & 0.485 & 0.699 \\
\hline
\end{tabular}

Source: data processed (2019) 
Table 5. Single linear regression of Attitude independent value with purchase intention toward general product and insecticide (continued).

\begin{tabular}{|r|r|r|r|r|r|r|r|}
\hline \multicolumn{2}{|c|}{ R square } & \multicolumn{2}{c|}{ Adj. R square } & \multicolumn{2}{c|}{ significant } & \multicolumn{2}{c|}{ Result } \\
\hline General & Insecticide & \multicolumn{1}{c|}{ General } & Insecticide & General & Insecticide & General & Insecticide \\
\hline 0.433 & 0.471 & 0.432 & 0.47 & $.000^{\prime}$ & .000 & Supported & Supported \\
\hline 0.433 & 0.489 & 0.432 & 0.488 & .000 & .000 & Supported & Supported \\
\hline
\end{tabular}

Source: data processed (2019)

Table 6. Multiple Linear Regression Of Behavior Independent Value With Purchase Intention Toward General Product And Insecticide

\begin{tabular}{|c|c|c|c|c|c|c|c|c|c|c|c|c|}
\hline frogendirt & $\mathrm{Meg}$ & & $9: 0$ & wats & , & 5 & B & & $3 x$ & kat & & 31 \\
\hline Eetaver & Oeneral & Issecticida & Gerend & Itsectrifis & Gosa: & Iserficide & Gerend & Isesebicida & Petane & hertcids & Cenerd & insericide \\
\hline Punchese ast dasery & 21063 & 4.842 & 08423 & $0.40 \%$ & 0444 & DASE & 323 & $400 \mathrm{~s}$ & 000 & & supotes & singotst \\
\hline Relsoitity & 4048 & 4.1944 & 0.78148 & BQHES & 0.353 & Q.165 & 3230 & 4.04 & 000 & 801 & Surouted & Siquonts \\
\hline
\end{tabular}

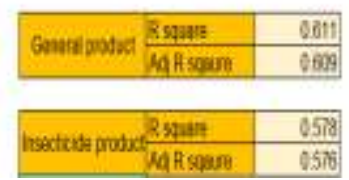

Source: data processed (2019)

H1: There will be a significant predictor of purchase intention toward general product via online channel by product/convenient, could explain the dependent value which purchases intention around $43.2 \%$ at a significant level of 0.05 or the 95\% confidence level. The P-values of all independent variables are less than 0.05 , which confirms the hypothesis is supported.

H2: There will be a significant predictor of purchase intention toward general product via online channel by customer service, which could explain the dependent value, which is around $43.2 \%$ at a significant level of 0.05 or the $95 \%$ confidence level. The P-values of all independent variables are less than 0.05 , which confirms that the hypothesis is supported.

H3: There will be a significant predictor of purchase intention toward general product via online channel by purchase and delivery, and reliability can be implied that all four independent variables around $61.1 \%$ at the significant level of 0.05 or the $95 \%$ confidence level. The P-values of all independent variables are less than 0.05 , which confirms that all the hypotheses, namely purchase and delivery, and reliability, are supported. As a result, purchase and delivery, and security have a statistically significant favorable influence on purchase intention. Procurement and distribution have the most statistically substantial beneficial impact on purchase intention with Standardized Coefficient at 0.444. The multicollinearity problem was also examined by verifying the Variance Inflation Factors (VIFs) and found no critical issues with all VIFs are less than 5.0.

H4: There will be a significant predictor of purchase intention toward insecticide products via online channel by product/convenient, which could explain the dependent value, which purchases intention around $47 \%$ at a significant level of 
0.05 or the $95 \%$ confidence level. The $\mathrm{P}$-values of all independent variables are less than 0.05 , which confirms the hypothesis is supported.

H5: There will be a significant predictor of purchase intention toward insecticide product via online channel by customer product, could explain the dependent value which purchases intention around $48.8 \%$ at the considerable level of 0.05 or the $95 \%$ of a certain level. The P-values of all independent variables are less than 0.05 , which confirms that the hypothesis is supported.

H6: There will be a significant predictor of purchase intention toward insecticide products via online channels by purchase and delivery. Reliability can be implied that all four independent variables are around $57.8 \%$ at the significant level of 0.05 or $95 \%$ of a certain level. The P-values of all independent variables are less than 0.05 , which confirms that all the hypotheses, namely purchase and delivery, and reliability are supported. As a result, purchase and delivery, and security have a statistically significant favorable influence on purchase intention. Procurement and distribution have the most statistically substantial beneficial impact on purchase intention with Standardized Coefficient at 0.609. The multicollinearity problem was also examined by verifying the Variance Inflation Factors (VIFs) of purchase and delivery, promotion, and product attribute found no critical issues with VIFs are less than 5.0.

\section{Conclusion and Suggestion}

\section{Discussion and Conclusion}

The purpose of this study was to comparison the customers' behavior intension regarding online shopping of general products and insecticide in Thailand. These predictions were based on the consumer's attitudes, perceptions of behavioral control, demographic, and personal characteristics. The Theory of Planned Behavior as outline topic, but the researchers use models in parallel data to the comparison between general product and insecticide.

Everyday customer's life is more hectic which their need to seek the method to simplify their life. The emphasis now is to do things faster and better as the online shopping trend keep going and have more innovation to customize customer need to shop via the internet as more and more people able to access the internet easily. These were some of the issues examined in this research, were analyzed in terms of attitude towards shopping medium. And perceptions of behavioral control were explored inhibitors of online shopping.

The behavioral five factors based on factor loading. These factors were: (1) Purchase and Delivery, (2) Reliability of Vendor, Factor analysis was also used to group products/services, based upon the intention to purchase also match the relationship with insecticide.

All 400 respondents were qualified to be the population samples applied in this study, which separated into 2 group purchase intentions of general product and gathered data to analyze purchase intention of general online product and 
insecticide product. The result of attitude was analyzed under single linear regression, and behavior correlates with three independent variables under multiple linear regression.

Focusing on the point of view for insecticide products to sell in the online channel. First of all, the attitude of the product and service. There is no different perception between the general product or insecticide product. Customers perceived that insecticide products have high quality, easy to use, safety concerns with reasonable points, and on-the-other service after sales are the point that makes a customer decide to purchase insecticide online. The next point of view is that the customer's behavior to make them choose to buy is purchase and delivery, and reliability. Procurement and distribution are more concerned with customer behavior which how they can get benefit if they purchase insecticide products online includes the method of the payment.

\section{Implication of The Study}

Future studies could compare the differences between intentions of shopping online and the demographics of people who respond to mail surveys with respondents who fill the survey out online. Having a broader sample will also lend itself to comparative analysis, facilitating market segmentation when retailing online.

\section{Limitation and Future Research Directions}

The online customer is a new business model that limited studies on customers' purchase intention in Thailand. The insecticide is not accessible and promotes the online channel that makes people did not concern about it. The same size in the research is a relatively small group. As the larger sample size and release time future, more might help generate more appropriate data and more precise findings. The sampling should be focusing all part in Thailand to measure more benefit to get from research. The perception of people doing research online is not attractive for the customer to spend a little time. As I release Facebook advertising, which people see an advertising link, more than 8.000 reaches, but online click to see the questionnaire only 300 reaches. The survey online must add some value to attract customers to click and do the research.

\section{References}

1. Ajzen, I. (1991). "The Theory of Planned Behavior. Organizational Behavior and Human Decision Process", 50, 179-211.

2. Applegate, Lynda M., McFarlan, F. W. \& McKenney, J. L. (1999). "Corporate Information Systems Management". Boston: Irwin McGrawHill.

3. Barker, Christian and Groenne, P. (1997). "Advertising on the Web", http://www.samkurser.dk/advertising/research.html.

4. Breitenbach, C. S. \& Van Doren, D. C. (1998). "Value-added marketing in the digital domain: enhancing the utility of the Internet. Journal of Consumer Marketing”, 15 (6), 558-575. 
5. Burke, R. R. (1997). "Real shopping in a virtual store". In R. A. Peterson (Ed.),

6. Electronic marketing and the consumer (pp. 81-88). Thousand Oaks, CA: SAGE Publications.

7. Clark, D. D. (1999). "High speed data races home. Scientific American", 281 (4), 94-99.

8. Harden, A. J. (1992). "Examination of women's attitudes towards electronic on-line in-home shopping for apparel information search and purchase". Unpublished doctoral dissertation. Ohio State University.

9. Hoffman, D. L. \& Novak, T. P. (1996). "Marketing in hypermedia computer-mediated environment: Conceptual foundations. Journal of Marketing", 60, 50-68.

10. Horowitz, A. S. (1996, November 18). "The next sales force. Computerworld", 30 (47) 126-130.

11. Jones, K. \& Biasiotto, M. (1999). "Internet retailing: current hype or future reality? The International Review of Retail", Distribution and Consumer Research, 9 (1), 69-79.

12. Klien, E. (1998, May/June). Plugging into electronic marketing. Retailing Trends, 38-40.

13. Kunz, M. B. (1997). On-line customers: "Identifying store, product and consumer attributes which influence shopping on the Internet”. Unpublished doctoral dissertation, University of Tennessee.

14. Mathwick, C. (1997). "A model of contextual antecedents and exchange outcomes of customer value: An empirical investigation into the catalog and Internet shopping context.

15. Unpublished doctoral dissertation, University of Tennessee. McBride, N. (1997). "Business use of the Internet: Strategic decision or another bandwagon". European Management Journal, 15 (1).

16. McMellon , C. A., Schiffman, L. G., \& Sherman, E. (1997). "Consuming cyberseniors: Some personal and situational characteristics that influence their online behavior". Advances in Consumer Research, 24, 517-521.

17. Murphy, R. (1998). The Internet: A viable strategy for fashion retail marketing? Journal of Fashion Marketing and Management", 3 (3), 209216.

18. Peter, J. P. \& Olson, J.C. (1999). "Consumer Behavior and Marketing Strategy $\left(5^{\text {th }}\right.$ Ed.)". Boston: Irwin, McGraw-Hill.

19. Peterson, R. A., Balasubramanian, S. \& Bronnenberg, B. J. (1997). "Exploring the implications of the Internet for consumer marketing". Journal of the Academy of Marketing Science, 25 (4), 329-346.

20. Radical Internet stirs up retailing. (1997). Facilities, 15 (11), 263-264. Reda, S. (1995, March). "Will consumers catch up with interactive shopping? Stores", 20-24.

21. Reynolds, J. (1997). "Retailing in computer mediated environments: electronic commerce across Europe". International Journal of Retailing \& Distribution Management, 25 (1), 29-37.

22. Thomsen, M. D. (1997), "Advertising on the Web", http://www.samkurser.dk/advertising/thomsen.html. 
23. Weeks, W. J., Brannon, E. L. \& Ulrich, P. V. (1998). "Generation X consumers preferences for non-store versus in-store shopping for apparel". Journal of Fashion Marketing and Management, 2 (2), 113-124. 